\title{
Crack growth rate prediction based on damage accumulation functions for creep-fatigue interaction
}

\author{
A.V. Tumanov, V.N. Shlyannikov, A.P. Zakharov \\ Institute of Power Engineering and Advanced Technologies, FRC Kazan Scientific Center, Russian Academy of Sciences, Russia \\ tymanof@@rambler.ru,shlyannikov@mail.ru, alex.zakharov88@mail.ru
}

\begin{abstract}
The present study is concerned with formulation of a model for the creep-fatigue crack growth rate prediction on the base of fracture damage zone concepts. It is supposed that crack growth rate can be determined by integration of damage accumulation rate equations into the fracture process zone for low-cycle fatigue and creep loading independently. In the case of low-cycle fatigue loading the damage accumulation function proposed by Ye and Wang was used as well as a classical Kachanov-Rabotnov power law was employment for the creep damage accumulation characterization. Fracture process zone size is calculated on the base of the nonlinear stress intensity factors concept proposed by Shlyannikov. The background for the proposed general model of crack growth rate under creep and fatigue interaction is given in order to comparison with the experimental data. Experimental study of crack growth rate under creep and fatigue interaction is performed for compact tension specimen made from 20CrMoV5. Crack growth rate carried out at the elevated temperature of $550^{\circ} \mathrm{C}$ according to ASTM E2760 standard. The predictions of the crack growth rate were compared with the experimental data for the $20 \mathrm{CrMoV} 5$ steel obtained at an elevated temperature, and the agreement was found to be satisfactory.
\end{abstract}

KEYwORDS. Creep-fatigue interaction; Crack growth rate prediction; Nonlinear stress intensity factors.

\section{open 0 access}

Citation: Tumanov A.V., Shlyannikov V.N., Zakharov A.P., Crack growth rate prediction based on damage accumulation functions for creep-fatigue interaction, Frattura ed Integrità Strutturale, 52 (2020) 299-309.

Received: 02.03 .2020

Accepted: 13.3 .2020

Published: 01.04.2020

Copyright: (C) 2020 This is an open access article under the terms of the CC-BY 4.0, which permits unrestricted use, distribution, and reproduction in any medium, provided the original author and source are credited.

\section{INTRODUCTION}

$\mathrm{S}$ tructures in the aviation, space flight, power generation, and petrochemical industries are typically exposed to elevated temperatures. Damage accumulation and growth considerations at creep and fatigue owing to changes in the material microstructure, void nucleation, interaction, and growth on the grain boundaries are important in the design and operation of such components in order to ensure structural integrity. It is well known that the creep damage accumulation from the damage caused by cyclic loading is different. At the moment, there are many models in literature allow to take into account the damage accumulation, both during creep and cyclic loading. 
The Hayhurst model [1] one of the generalized models for the creep damage accumulation. The main disadvantage of this model is necessity to use six parameters as material properties in order to describe the damage accumulation behavior. Moreover, the parameters determination methods are mainly indirect. According to this, the Rabotnov-Kachanov model is used due to the direct method of material constants determination.

The Lemaitre model [2] is the one of the most frequently used for the fatigue damage accumulation behavior. In similar phenomenological models using the tensor damage parameter leads to considerable difficulties for material constants determination. For the different creep and fatigue laws if the stress state is unchanged the scalar, vector, and tensor damage parameters give almost identical results. In this regard, models with a scalar damage parameter as a simplified alternative can be considered [3-6].

The main problem of the residual life prediction under the creep-fatigue loading conditions is the complex character of their interaction [7-10]. Statistical approximations of experimental results by the polynomial functions are most common approach of the creep-fatigue interaction behavior. In present study, continuum damage mechanics is applied to assess the creep-fatigue interaction and the crack growth rate prediction, considering the complete sequence of formulations.

\section{FATigue dAMAgE ACCUMUlation RATE}

he variable critical distance is one of important parameter in modern fracture mechanics, denoted to as the fracture process zone size. A general assumption regarding the distance criterion under elastic-plastic and creep loading conditions is that a crack increment occurs when the fracture resistance parameter (stress, strain, or energy) reaches a critical value at a characteristic distance from the crack tip.

In creep-fatigue interaction both the fatigue and the creep crack growth rate can be obtained from damage accumulation rule independently. The crack size is assumed to increase when the local strain energy density at the crack tip reaches the critical value. Hence, a material point initially at a characteristic distance, $r_{c}$, ahead of the crack tip, $r=0$, moves to the tip both in time $\Delta t$ after an increment in the crack growth for creep and in number of cycles $\Delta N$, in case of fatigue. It is assumed that the crack length increment equal to the fracture process zone size, $\Delta a=r_{f}$, and the crack growth rate, $\dot{a}$, becomes [11-12]:

$$
\dot{a}_{f}=\int_{0}^{r_{f}} \dot{\omega}\left(r_{f}\right) d r_{f}
$$

where $\dot{\omega}\left(r_{f}\right)$ is the damage accumulation rate.

Eqn. (1) for creep conditions was proposed initially, however the analogy between the creep time $\Delta t$ and the number of cycles $\Delta N$ makes possible to use this dependence for low cycle fatigue. Usually, the one of the main characteristic in models with a scalar damage parameter is the number of cycles before fracture $N_{f}$ at the stress amplitude $\sigma_{a}$. In the simplest case of uniaxial tension-compression, the fatigue life can be obtained from:

$$
2 N_{f}=\left(\frac{\sigma_{a}}{\sigma_{f}^{\prime}}\right)^{\frac{1}{c}}
$$

where $\sigma_{f}^{\prime}$ and $c$ are fatigue constants.

The damage parameter at constant stress amplitude according to [13]

$$
\omega_{f}=-\frac{\omega_{f_{N-1}}}{\ln N_{f}} \ln \left[1-\frac{N}{N_{f}}\right]
$$

where $\omega_{f_{N-1}}$ - the critical value of the damage parameter in the penultimate cycle and it is associated with static toughness $U_{T 0}$ by the following relationship: 


$$
\omega_{f_{N-1}}=1-\frac{\sigma_{a}^{2}}{2 E U_{T 0}}
$$

where E - Young's modulus.

The fatigue damage accumulation rate can be obtained from the equation (3)

$$
\dot{\omega}_{f}=\frac{d \omega_{f}}{d N}=\frac{\omega_{f_{N-1}}}{\left[\left(N_{f}-N\right) \ln N_{f}\right]}
$$

\section{FATIGUE CRACK GROWTH RATE}

$\mathrm{F}$

or Ramberg-Osgood hardening law [26] the critical value of a strain energy density $W_{c}$ can be obtained from true stress-strain diagram:

$$
W_{c}=\int_{0}^{\sigma_{f}}\left[\frac{\sigma}{E}+\alpha \frac{\sigma_{y}}{E}\left(\frac{\sigma}{\sigma_{y}}\right)^{n_{p}}\right] d \sigma
$$

where $\alpha$ - is the strain hardening coefficient, $n_{p}$ - is the strain hardening exponent, $\sigma_{y}$ - is the yield stress, $\sigma_{f}$ - ultimate tensile stress.

According to the classical Hutchinson-Rosengren-Rice model in the zone where fully plastic singularity is dominated the strain energy density $W$ can be found from following expression [14]:

$$
W=\alpha \frac{n_{p}}{n_{p}+1} K_{p}^{n_{p}+1} \tilde{\sigma}_{e}^{n_{p}+1} \frac{\sigma_{y}^{2}}{E} \frac{\left(1-v^{2}\right)}{\bar{r}}
$$

where $v$ - is Poisson's ratio, $\bar{r}=r / a$ - crack tip distance, $a$ - crack length, $\tilde{\sigma}_{e}$ - dimensionless equivalent Mises stresses which depend only on a polar coordinate $\theta$ and normalized by $\left.\tilde{\sigma}_{e}(\theta)\right|^{\max }=1$. The plastic stress intensity factor $K_{P}$ in small-scale and extensive yielding conditions in Eqn.(7) can be expressed directly using Rice's J-integral [15]. That is

$$
\bar{K}_{P}=\left[\frac{J E}{\alpha_{p} \sigma_{y}^{2} I_{p} L}\right]^{\frac{1}{n_{p}+1}}
$$

where

$$
\begin{aligned}
J=\frac{r \sigma_{y}^{2}}{E} \int_{-\pi}^{+\pi}\left[\frac{1+v}{3} \bar{\sigma}_{e}^{2}+\frac{1-2 v}{6} \bar{\sigma}_{k k}^{2}+\frac{\alpha_{p} n}{n+1} \bar{\sigma}_{e}^{n+1}\right] \cos \theta d \theta- \\
\quad-r \sigma_{y} \int_{-\pi}^{+\pi}\left(\bar{\sigma}_{r r} \frac{\partial \bar{u}_{r}}{\partial r}+\bar{\sigma}_{r \theta} \frac{\partial \bar{u}_{\theta}}{\partial r}\right) \cos \theta d \theta+\sigma_{y} \int_{-\pi}^{+\pi}\left(\bar{\sigma}_{r r} \frac{\partial \bar{u}_{r}}{\partial \theta}+\bar{\sigma}_{r \theta} \frac{\partial \bar{u}_{\theta}}{\partial \theta}\right) \sin \theta d \theta
\end{aligned}
$$

In Eqns. (8-9), $\bar{u}_{i}$ are crack tip dimensionless displacement components, $L$ is cracked body characteristic size, in our case is the crack length $L=a$, and $I_{p}$ is the numerical constant of the crack-tip stress-strain field, which should be 
determined for the cracked body with a finite size. In the case of full three-dimensional cracked body, the $I_{p}$-factor in Eqn. (8) changes not only with the strain hardening exponent $n_{p}$ but also with the position along the crack front. In Eqn. (9), the stress tensor and invariant are both normalized by the yield stress: $\bar{\sigma}_{i j}=\sigma_{i j} / \sigma_{y}$ and $\bar{\sigma}_{k k}=\sigma_{k k} / \sigma_{y}$. More detail in determining the $I_{p}$ factor for different elastic-plastic cracked body configurations are given by Refs. [15-18]. In a first approximation the crack growth as a static cracks sequence is considered. Thus, the path independent J-integral can be obtained from:

$$
J=\frac{K_{1}^{2}\left(1-v^{2}\right)}{E}
$$

Substitution Eqns. (6) and (8) into (7) give a possibility to obtain the critical distance where the strain energy density reaches a critical value:

$$
\bar{r}_{f}=\alpha \frac{n}{n+1} K_{p}^{n_{p}+1} \tilde{\sigma}_{e}^{n_{p}+1} \frac{\sigma_{y}^{2}}{E} \frac{\left(1-v^{2}\right)}{W_{c}}
$$

The fatigue crack growth rate can be calculated by substitution Eqns. (5) and (11) into (1) directly, it leads to the following relationship:

$$
\left(\frac{d a}{d N}\right)_{\text {fatigue }}=\int_{0}^{r_{f}} \dot{\omega}_{f} d r=a \sigma_{y}^{2} \tilde{\sigma}_{e}^{n_{p}+1} K_{p}^{n_{p}+1} \frac{\alpha n_{p}}{n_{p}+1}\left[\frac{\sigma_{y}^{2} \tilde{\sigma}_{e}^{2} r_{f}^{\frac{2}{n_{p}+1}} K_{p}^{2}}{2 E U_{t 0}}-1\right] \frac{\left(1-v^{2}\right)}{E W_{c} \ln \left(N_{f}\right)\left(N-N_{f}\right)}
$$

\section{CReep damage ACCUMUlation}

$\mathrm{I}$

$\mathrm{n}$ this study the classical Kachanov-Rabotnov power law is used for the creep damage accumulation description. According to this model, the strain rate during creep is [1-2]:

$$
\dot{\varepsilon}_{e}=B\left(\frac{\sigma_{e}}{1-\omega_{\sigma r}}\right)^{n_{r}}
$$

and the creep damage accumulation rate is:

$$
\omega_{c r}=\frac{d \omega_{c r}}{d t}=D\left(\frac{\sigma_{e}}{1-\omega_{c r}}\right)^{m}
$$

where $B$ and $n_{c r}$ are material constants of the Norton power law constitutive equation, $D$ and $m$ - are material properties. The damage variable $\omega$ indicate the measure of creep damage with $\omega=0$ denoting the undamaged state and $\omega=1$ the fully damaged state. The creep damage increment $\Delta \omega_{\sigma r}$ at time $\Delta t$ can be obtained by integrating the expression (14):

$$
. \Delta \omega_{\sigma r}=1-\left[\left(-D \sigma^{m} \Delta t-C_{3}\right)(m+1)\right]^{\frac{1}{m+1}} .
$$

where $C_{3}$ - is integration constant. This constant can be determined from the initial state. 


$$
C_{3}=-\frac{\left(1-\omega_{0}\right)^{m+1}}{m+1}-D \sigma_{e}^{\prime \prime} t_{0}
$$

Based on the fact that the damage parameter is equal to one at failure $\omega=1$ the fracture time at the known stress level can be calculated directly:

$$
t_{c r}=\frac{1}{(m+1) D \sigma_{e}^{m}}
$$

\section{CREEP CRACK GROWTH RATE}

$\mathrm{F}$

or elastic-nonlinear-viscous material behavior, the stress, strain and displacement rate fields can be use in order to account for a creep stress intensity factor $K_{c r}$, which is amplitude of singularity. For extensive creep conditions the relation between the $C$-integral and creep stress intensity factor is introduced by the authors [19] in the form:

$$
\begin{aligned}
& \bar{K}_{c r}=\frac{1}{\sigma_{r e f}}\left(\frac{C^{*}}{B I_{c r} L}\right)^{\frac{1}{n_{r r}+1}} \\
& C^{*}=\int_{-\pi}^{+\pi} B r \frac{n_{c r}}{n_{c r}+1} \sigma_{e}^{n_{r r}+1} \cos \theta d \theta- \\
& \quad-\int_{-\pi}^{+\pi}\left[\sin \theta\left(\sigma_{r r} \frac{\partial \dot{u}_{r}}{\partial \theta}+\sigma_{r \theta} \frac{\partial \dot{u}_{\theta}}{\partial \theta}\right)-r \cos \theta\left(\sigma_{r r} \frac{\partial \dot{u}_{r}}{\partial r}+\sigma_{r \theta} \frac{\partial \dot{u}_{\theta}}{\partial r}\right)\right] d \theta
\end{aligned}
$$

where $\sigma_{r f}$ - is reference stress, $K_{c r}$ is amplitude of singularity in the form of creep stress intensity factor, $C^{*}$ is the $C$ integral, $\dot{u}_{i}$ are displacement rate angular functions, $\sigma_{i j}$ are stress components. It should be noted that the $I_{c r}$ - integral values are determined similar to $I_{p}$ and can be determined directly from the finite element analysis by distribution of the displacement rate functions, $\dot{\tilde{u}}_{i}$, and dimensionless angular stress functions, $\tilde{\sigma}_{i j}$, [9]. More detail in determining the $I_{c r}$ integral for different creeping cracked body geometries are given by Refs. [12, 19-22].

For a static crack in the outer region of the small-scale creep zone, the elastic crack-tip field still dominates. In this case, the expression of $C$-integral has a simple form [5]:

$$
C(t)=\frac{K_{1}^{2}\left(1-v^{2}\right)}{E\left(n_{c r}+1\right) t_{c r}}
$$

The elastic stress intensity factor for a compact tension specimen is [23]:

$$
K_{1}=\frac{F}{b \sqrt{w}} Y_{1}
$$

where $F$ - is applied load, $Y_{1}$ - is geometry correction function:

$$
Y_{1}=\frac{(2+a / w)}{(1-a / w)^{3 / 2}}\left(0.886+4.64 a / w-13.31\left(\frac{a}{w}\right)^{2}+14.72\left(\frac{a}{w}\right)^{3}-5.6\left(\frac{a}{w}\right)^{4}\right.
$$


The creep crack growth rate was determined based on the assumption that the crack propagation energy is equivalent to the damage initiation energy in infinite plate. Thus, the infinite plate remote stresses were calculated from the following expression:

$$
\sigma_{r f}=\frac{K_{1}}{\sqrt{\pi a}}
$$

Substitution Eqn.(23) into (17) give a possibility to calculate a reference failure time. A strain energy rate density parameter, $\dot{W}$, is employed by the author [20] to obtain the critical distance, $r_{r r}$, in the crack tip vicinity under creep conditions. If $\sigma_{f c}$ referred the maximum value of the creep-rupture strength at a specified temperature and creep time, then the creep crack tip critical distance $r=r_{c r}$ is given by expression:

$$
r_{c r}=a\left(\frac{\bar{K}_{c r}}{\bar{\sigma}_{f c}}\right) \tilde{\sigma}_{e}^{n_{c r}+1}
$$

where $\tilde{\sigma}_{e}$ is the dimensionless equivalent von Mises stress. Substitution of Eqns. (14) and (24) into Eqn. (1) with take into account that $r_{c r}=a \bar{r}_{r r}$, and integrating leads to the equation for creep crack growth in terms of $C^{*}$-integral and creep stress intensity factor $\bar{K}_{c r}$ :

$$
\left(\frac{d a}{d t}\right)_{\text {creep }}=\int_{0}^{r_{r r}} \omega_{c r} d r=a D\left(\frac{\tilde{\sigma}_{e}}{\bar{\sigma}_{f c}} K_{c r}\right)^{n+1}\left(\frac{\sigma_{f c}}{K_{c r}^{2}}\right)^{m}\left[\left(1-\omega_{0}\right)^{m+1}+D(m+1)\left(\frac{\sigma_{f c}}{K_{c r}^{2}}\right)^{m}\left(t_{0}-t\right)\right]^{-\frac{m}{m+1}}
$$

\section{CREEP-FATIGUE INTERACTION}

7 he general simple superposition lifetime prediction models for creep-fatigue interaction can be differentiated as those that account for the hold-time effects and those that are employed for continuous cyclic scenarios. Therefore, we will use a linear summation law for creep-fatigue crack growth rate prediction $[22,24]$

$$
\begin{aligned}
& \frac{d a}{d N}=\left(\frac{d a}{d N}\right)_{\text {fatigue }}+\left(\frac{d a}{d N}\right)_{\text {creep }}=\left(\frac{d a}{d N}\right)_{\text {fatigue }}+\frac{1}{3600 f}\left(\frac{d a}{d t}\right)_{\text {creep }} \\
& \frac{d a}{d t}=\left(\frac{d a}{d t}\right)_{\text {fatigue }}+\left(\frac{d a}{d t}\right)_{\text {creep }}=3600 f\left(\frac{d a}{d N}\right)_{\text {fatigue }}+\left(\frac{d a}{d t}\right)_{\text {creep }}
\end{aligned}
$$

where $d a / d t$ is crack growth rate in $\mathrm{mm} /$ hour, $d a / d N$ is crack growth rate per cycle ( $\mathrm{mm} /$ cycle), and $f$ is frequency in $\mathrm{Hz}$. It is well known that the creep damage accumulation is different from damage caused by cyclic loading. According to this a fracture process zone will be different for both creep and fatigue cases.

\section{MATERIAL PROPERTIES}

T he material used in the tests and numerical calculations is $20 \mathrm{CrMoV} 5$ steel, which is used for main power plant components such as steam piping and reheat tubes. All mechanical properties were obtained on smoothed round specimens. Uniaxial tension and fatigue tests on the BISS Nano $25 \mathrm{kN}$ servo-hydraulic test system according to ASTM E8, E466 and E646 standards were performed. Creep and damage accumulation law properties were obtained by using UTS-1300-1-50-1-A test system. More details about creep damage accumulation law constants determination 
algorithm can be found in [27]. The main mechanical properties of analyzed material were obtained at the elevated temperature of $550^{\circ} \mathrm{C}$ and summarized in Tab. 1.

\begin{tabular}{ll}
\hline Property & Value \\
\hline Young's modulus, E [GPa] & 154 \\
Poisson's ratio, $v$ & 0.3 \\
Strain hardening coefficient, $\alpha$ & 2.06 \\
Strain hardening exponent, $\mathrm{n}_{\mathrm{p}}$ & 8.22 \\
Yield stres, $\sigma_{0}[\mathrm{MPa}]$ & 265 \\
Ultimate true tensile strength, $\sigma_{\mathrm{f}}[\mathrm{MPa}]$ & 577 \\
Norton's constant, $\mathrm{B}\left[1 /\left(\mathrm{Pa}{ }^{\wedge} \mathrm{n} \cdot \mathrm{hr}\right)\right]$ & $0.57 \times 10^{-24}$ \\
Norton's constant, $\mathrm{n}_{\mathrm{cr}}$ & 2.52 \\
Damage constant, $\mathrm{D}\left[1 /\left(\mathrm{Pa}{ }^{\wedge} \mathrm{n} \cdot \mathrm{hr}\right)\right]$ & $0.54 \times 10^{-24}$ \\
Damage constant, $\mathrm{m}$ & 2.8 \\
Fatigue strength coefficient, $\sigma_{\mathrm{f}}^{\prime}[\mathrm{MPa}]$ & 750 \\
Fatigue coefficient, c & -0.087 \\
\hline
\end{tabular}

Table 1: The main mechanical properties of 20CrMoV5 steel.

The creep-rupture strength $\sigma_{f c}$ at a specified temperature $T$ (Kelvin) and creep time $t$ (hours) for 20CrMoV5 steel approximately can be found from the following equation [25]:

$$
\begin{aligned}
& \sigma_{f c}=(-156.38 \cdot \ln (G)+586.36) \\
& G=T(\ln (t)-2 \ln (T)-24.1) \cdot 10^{-3}
\end{aligned}
$$

\section{EXPERIMENTAL STUDY}

$\mathrm{O}$

ne of the main purposes of this present work is to study the influence of the damage accumulation on the creep-fatigue crack growth rate. To this end, subjects for both the experimental studies and numerical analyses are compact tension specimens, which are the most frequently used for characterizing the crack growth rate resistance. In general, the selected dimensions are as recommended by the ASTM test standard [23]. The length of the specimen working area was chosen $w=50 \mathrm{~mm}$ and specimen thickness $b=12.5 \mathrm{~mm}$.

The creep-fatigue tests were carried out on the UTS-110MH-5-0U test system with a high-temperature oven and highprecision crack opening displacement extensometer (Fig. 1a). The potential drop and unloading compliance methods were used to monitor the crack length during the tests. The waveforms for the loading and unloading portions were trapezoidal, and the loading/unloading times were maintained constant ( $5 \mathrm{~s}$ rise and decay times). A hold time of a predetermined duration, namely $60 \mathrm{~s}$, was superimposed on the trapezoidal waveforms at the maximum load. Parts of the $5 \mathrm{~s}$ loading and unloading cycles represent low-cycle deformation, while the $60 \mathrm{~s}$ dwell under a constant load represents creep (Fig. 1b).

The tests were conducted at $550^{\circ} \mathrm{C}$ on special high-temperature test equipment with a load ratio $\mathrm{R}$ of 0.1 and maximum load value $P_{\max }$ of $11 \mathrm{kN}$. The specimens were pre-cracked to an initial crack length-to-width ratio $a / w$ of approximately 0.36 to 0.39 under cyclic loading at room temperature. For each tested specimen during the creep-fatigue tests the 
amplitude ratio was changed from $R=0.1$ to $R=0.9$ two times for a short time period. This practice helped to determine the intermediate crack front positions during the creep-fatigue loading between the initial (pre-crack) and the final crack fronts (Fig.2).

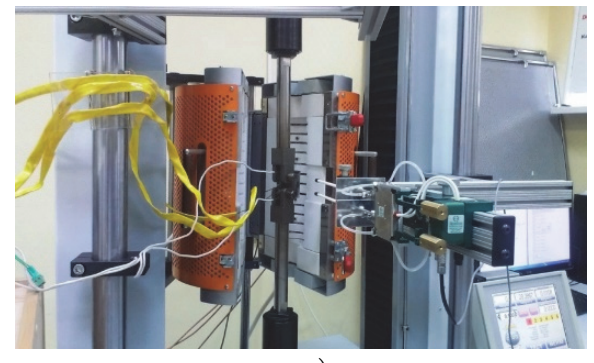

a)

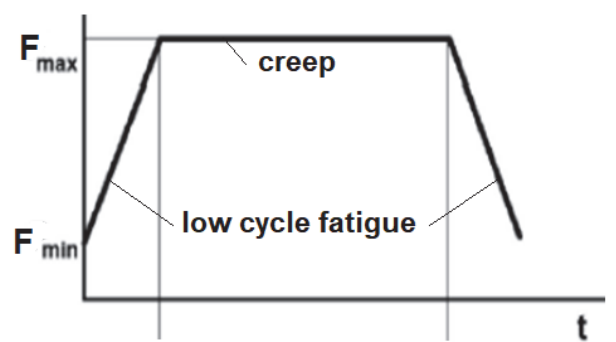

b)

Figure 1: Tests equipment (a) and the load waveform (b).

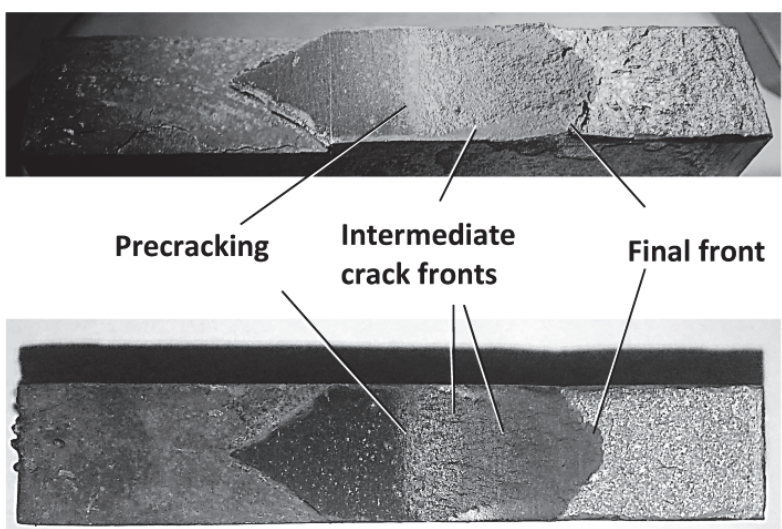

Figure 2: Fracture surfaces.

After total failure of the specimen, measurements of the crack sizes were taken for four positions of the crack front by means of an optical microscope. For each front, the crack size at five equally spaced points centered on the specimen midthickness line was measured along the crack front.
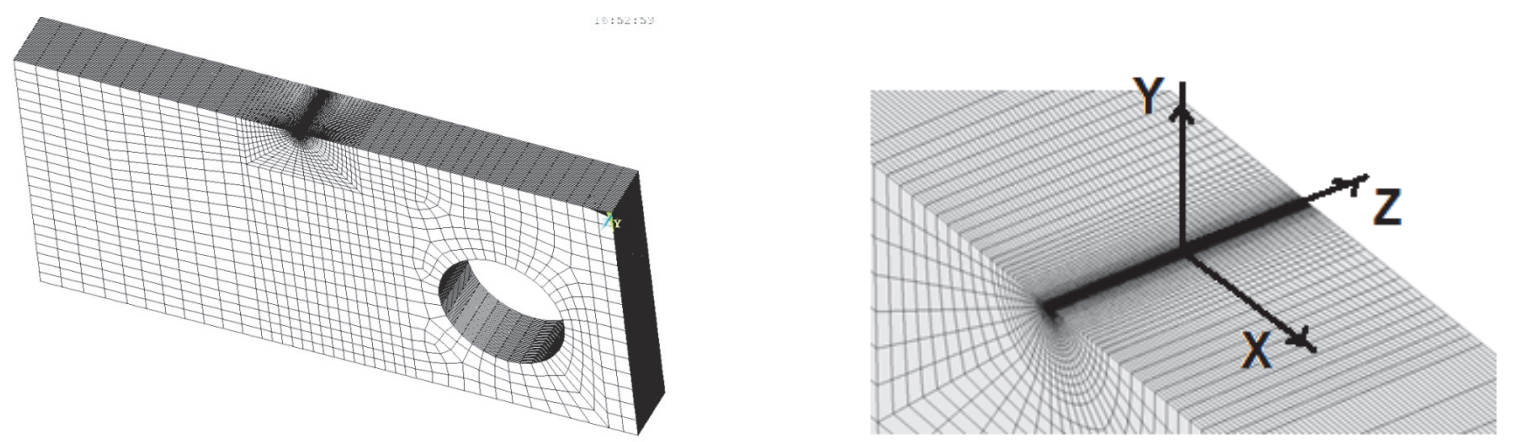

Figure 3: Finite element method meshes for compact tension specimen.

\section{FINITE ELEMENT MODEL}

ull-field finite element analysis is performed using ANSYS software to study the crack-front stress fields for compact tension specimen. Along the thickness direction, an identical planar mesh is repeated from the symmetry plane to the free surface. To catch the drastic change of the stress field near the free surface, the thickness of 
successive finite element layers is exponentially reduced from the mid-plane toward the free surface. The radial sizes of the finite elements are varied according to the geometric progression. According to the symmetrical properties, one quarter of the actual structure was selected to establish the three-dimensional finite element model. The twenty-node quadrilateral brick isoparametric three-dimensional solid elements were used to model for the specimen configuration. Typical finite element meshes for the compact tension specimen are illustrated in Fig. 3

Programming of the numerical calculations includes the analysis for the specified experimental combinations of creep time/number of fatigue cycles and crack length in a compact specimen. Three position of the crack front were considered $(a / w=0.38,0.55$ and 0.7$)$. For $a / w=0.55$ and 0.7 a curvilinear crack fronts were simulated.

\section{RESULTS AND DISCUSSION}

$\mathrm{A}$

$\mathrm{s}$ result of a finite element simulations a stress-strain fields were obtained for different combinations of crack length and creep time. The governing parameter behavior of crack tip fields $I$ for the compact specimen is plotted in Fig. 4 along the crack front towards the thickness direction.

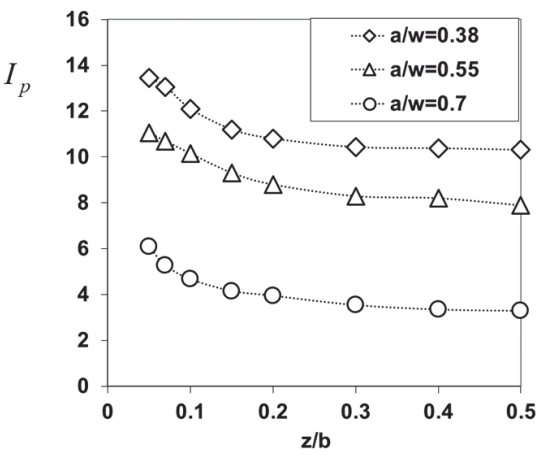

a)

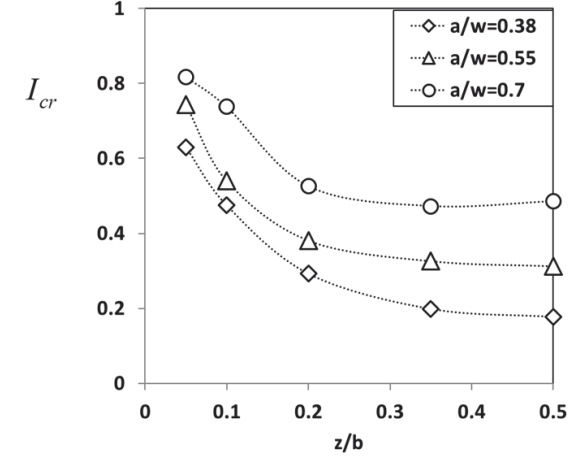

b)

Figure 4: I -factor distributions along crack front for plastic (a) and creep (b) state.

It should be noted that in real solids, the governing parameter of the crack tip field the $I$-integral is very sensitive to variations of the material properties, load level and geometry. These distributions of the In-integral are used to calculate the nonlinear stress intensity factors in the compact tension specimen.

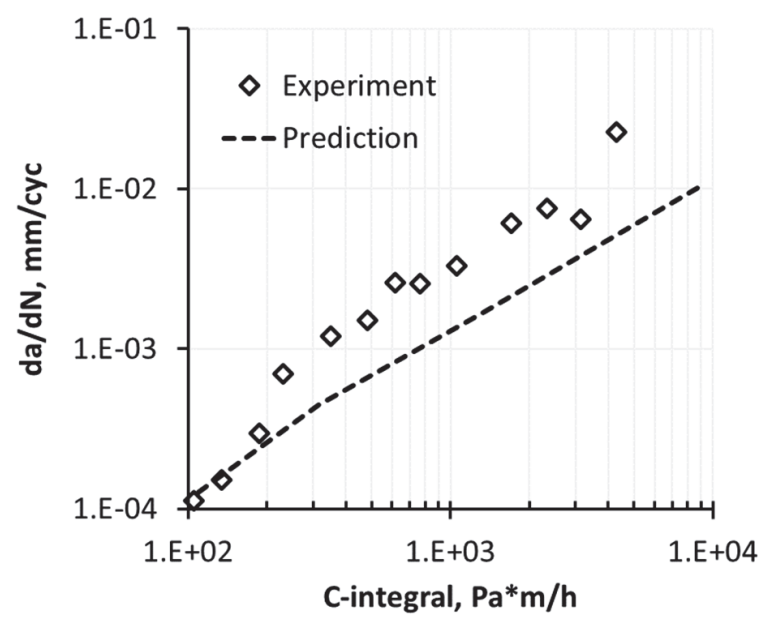

Figure 5: Comparison of crack growth rate prediction with experimental results for steel 20CrMoV5.

The main objective of the creep-fatigue tests is to provide substantiation for the theoretical models. Fig. 5 illustrates the prediction of the creep-fatigue crack growth rate for the $20 \mathrm{Cr} 1 \mathrm{MoV} 5$ steel plotted against $C^{*}$-integral for the compact tension specimen. The experimental $C^{*}$-integral values were obtained from the crack length, determined using the 
technique according to ASTM E2760 [23]. The experimental data of all tested specimens fall within a relatively narrow scatter band. A good agreement with the theoretical predictions is observed. By the author opinion the shift between prediction and experiment is caused by default value of initial damage $\mathrm{w} 0$ for each finite element model. In real specimens the value of initial damage during creep-fatigue depends on load history. For short cracks and small creep times it can be neglected, but Influence over time enhanced. The proposed models of the crack growth rate are formulated in terms of nonlinear stress intensity factors. This model can describe the behavior a wide range of the material different properties for creep-fatigue interaction.

\section{ACKNOWLEDGES}

7 he authors gratefully acknowledge the financial support of the Russian Science Foundation under the Project 1879-00279.

\section{REFERENCES}

[1] Rabotnov YN. (1969) Creep problems in structure members. North-Holland, Amsterdam, 822. DOI: $10.1002 /$ zamm.19710510726.

[2] Kachanov LM. (1986) Introduction to Continuum Damage Mechanics. Martinus-Nijhoff, Dordrecht, 135 DOI: 10.1002/nag.1610110509.

[3] Brathe L. (1978) Estimation of Kachanov parameters and extrapolation from isothermal creep rupture data. Int J Mech Sci., 20, pp. 617-624. DOI: 10.1016/0020-7403(78)90020-6.

[4] Hutchinson, J.W. (1983) Constitutive behavior and crack tip fields for materials undergoing creep-constrained grain boundary cavitation, Acta Metall., 31, pp. 1079-1088. DOI: 10.1016/0001-6160(83)90204-3.

[5] Riedel H. (1987) Fracture at high temperatures. Berlin: Springer-Verlag, 418. DOI: 10.1002/crat.2170230609.

[6] Bendick W. (1991) Analysis of material exhaustion and damage by creep. Int J Pres Ves Piping, 47, pp. 57-78. DOI: 10.1016/0308-0161(91)90086-H.

[7] Budden J.P., Ainsworth R.A. (1997) The effect of constraint on creep fracture assessments. Int. J. Fract., 87, pp. 139-149. DOI: 10.1016/0029-5493(92)90175-U.

[8] Wen JF, Tu ST. (2014) A multiaxial creep-damage model for creep crack growth considering cavity growth and microcrack interaction. Eng Fract Mech, 123, pp. pp. 197-210. DOI: 10.1016/j.engfracmech.2014.03.001.

[9] Katanakha N.A., Semenov A.S., Getsov L.B. (2015) Durability of Bends in High-Temperature Steam Lines under der Conditions of Long-Term Operation./Thermal Engineeting, 62(4), pp. 260-270. DOI: 10.1134/S0040601515040047.

[10] Corten H.T. and Dolan T.J. (1956) Cumulative fatigue damage. In: Proceedings of the international conference on fatigue of metals, Institute of Mechanical Engineering, London, pp. 235-246.

[11] Budden P.J., Ainsworth R.A. (1997) The effect of constraint on creep fracture assessments. Int. J. Fract., 87, pp. 139149. DOI: $10.1023 /$ A:1007416926604.

[12] Shlyannikov V.N., Ishtyryakov I.S., Tumanov A.V. (2020) Characterization of the nonlinear fracture resistance parameters for an aviation GTE turbine disc. Fatigue Fract Eng Mater Struct, pp. 1-17. DOI: 10.1111/ffe.13188.

[13] Ye D.Y. and Wang Z.L. (2001) A new approach to low-cycle fatigue damage based on exhaustion of static toughness and dissipation of cyclic plastic strain energy during fatigue. International Journal of Fatigue, 23, pp. 679-687. DOI: $10.1177 / 1056789512456030$.

[14] Hutchinson J.W. (1968) Plastic stress and strain fields at a crack tip. J. Mech. Phys. Solids. 16, pp. 337-347. DOI: 10.1016/0022-5096(68)90021-5

[15] Shlyannikov V.N., Tumanov A.V. (2014) Characterization of crack tip stress fields in test specimens using mode mixity parameters, Int. J. Fract. 185, pp. 49-76. DOI: 10.1007/s10704-013-9898-0

[16] Shlyannikov V.N., Boychenko N.V., Tumanov A.V., Fernandez-Canteli A. (2014) The elastic and plastic constraint parameters for three-dimensional problems, Eng. Fract. Mech. 127, pp. 83-96.

DOI: 10.1016/j.engfracmech.2014.05.015

[17] Shlyannikov V.N., Boychenko N.V., Fernandez-Canteli A., Muniz-Calvente M. (2015) Elastic and plastic parts of strain energy density in critical distance determination, Eng. Fract. Mech. 147, pp. 100-118.

DOI: $10.1016 /$ j.engfracmech.2015.08.024. 
[18] Shlyannikov V.N., Yarullin R.R., Zakharov A.P. (2016) Structural integrity assessment of turbine disk on a plastic stress intensity factor basis, Int. J. Fatigue 92, pp. 234-245. DOI: 10.1016/j.ijfatigue.2016.07.016.

[19] Shlyannikov V.N., Tumanov, A.V., Boychenko, N.V. (2015) A creep stress intensity factor approach to creep-fatigue crack growth, Eng. Fract. Mech. 142, pp. 201-219. DOI: 10.1016/j.engfracmech.2015.05.056.

[20] Shlyannikov V.N. (2017) Critical distance for creep crack growth problems, Eng. Fract. Mech. 176, pp. 126-143. DOI: 10.1016/j.engfracmech.2017.03.001.

[21] Shlyannikov, V.N., Tumanov, A.V. (2018). Creep damage and stress intensity factor assessment for plane multi-axial and three-dimensional problems, Int. J. Solids Struct. 150, pp. 166-183. DOI: 10.1016/j.ijsolstr.2018.06.009.

[22] Shlyannikov V.N. (2019) Creep-fatigue crack growth rate prediction based on fracture damage zone models. Eng. Fract. Mech., 214, pp. 449-463. DOI: 10.1016/j.engfracmech.2019.04.017.

[23] ASTM E2760-19. (2019) Standard test method for creep-fatigue crack growth testing. Annual book of ASTM standards. Philadelphia (PA): American Society for Testing and Materials. DOI: 10.1520/E2760-19.

[24] Skelton R.P., Gandy D. (2008) Creep-fatigue damage accumulation and interaction diagram based on metallographic interpretation of mechanisms. Mater. High Temp. 25, pp. 27-54. DOI: 10.3184/096034007X300494 .

[25] Guidelines for the heat resistance characteristics and durability of metals determination CO 153-34.17.471-2003 Ministry of energy of Russian Federation. Moscow (2004). pp. 95

[26] Ramberg W., \& Osgood W. R. (1943). Description of stress-strain curves by three parameters. Technical Note No. 902, National Advisory Committee For Aeronautics, Washington DC.

[27] Tumanov A.V., Shlyannikov (2018) V.N. Method for creep damage accumulation law constants determination. Transactions of Academenergo. 4, pp. 115-126. 